\title{
STRENGTH OF AGED WOOD IN OLD CONSTRUCTIONS
}

\author{
Vladimir Fedyukov*, Vasilii Chernov, Maria Chernova \\ Volga State University of Technology, Russian Federation
}

The results of comprehensive research into spruce and pine wood in a structure after 70 years of its exploitation are presented. Significant changes in the wood in terms of compressive strength along the grain and static bending across the grain were revealed compared with fresh wood. The magnitude of these changes depends on the location of wood in the walls of the structure relative to the cardinal points.

Key words: spruce and pine wood, equilibrium moisture content, specified moisture content, ultimate compressive strengthalong the grain, static bending ultimate tensile strength across the grain

\section{INTRODUCTION}

In many regions of Russia today there is a relocation of rural residents to cities. For example, the number of rural settlements without residents (empty settlements, i.e. different types of villages, hamlets), according to the 2010 census, amounted to 19,439 in the Russian Federation, including the Volga-Vyatka economic region, where these scientific studies have been carried out and the main building material is spruce and pine wood, where 1,830 villages are without residents. Approximate calculations based on the average of 10-15 buildings in one settlement, each one containing at least $30 \mathrm{~m} 3$ of wood, show that the total amount of wood in abandoned villages and hamlets in Russia today is more than $500,000.0 \mathrm{~m} 3$. For comparison, approximately 2.5-3.0 thousand hectares of ripe coniferous stands of medium productivity have such a supply of wood.

In addition, even in functioning settlements, there are also many empty wooden structures today due tothe construction of new brick cottages.

Today, such timber is used at best as firewood, and it often decomposes on-site, creating inadequate sanitary and fire hazard environment. At the same time, due to intensive tree harvesting and under the influence of adverse climatic and anthropogenic factors, forest areas are sharply reduced, especially in the European region. In the nearest future, this could lead to severe environmental consequences: forests are the 'lungs' of the planet and each earthman breathes oxygen produced through photosynthesis in forests for 10 hours a day [1, 2].

Studies of physical and mechanical properties of old wood in structures have still been extremely scarce, and the results are very contradictory. Some authors obtained results confirming an increase in density, elastic modulus, tensile strength under static bending, and other parameters of old wood compared to fresh wood of both coniferous and deciduous species [3-5].

Some works cite opposite results. For example, after aging in a log house for 120 and 130 years, there was a slight decrease in strength and stiffness of larch wood [6]. In [7], the properties of wood in structural elements of 75-100-year-old wooden buildings are studied. It was found out that after long-term exploitation, the wood haslower than usual compressive and bending strength by $10 \%$, tensile strength is lower by approximately $20 \%$ and cleaving - by about $30 \%$ in comparison with standard data.

Modern works in the field of wood aging include the research of Professor Navi (Switzerland), who studied coniferous wood, mainly spruce. In his works, he came to the conclusion that it is possible to predict and control changes in the properties of wood, if we consider the aging process as structural changes in an unstable glassy state, based on the parameters of ambient temperature and pressure, as well as mechanical loads and internal stresses [8].

The fundamental work of K. Kranitz, P. Niemz et al. (Germany) should also be considered [9]. Their results confirm the fact that aged wood has higher values of dynamic modulus of elasticity in the longitudinal and radial directions. However, its significant difference in the tangential direction was not found. The shear modulus of fresh and aged wood did not have significant differences either. The assumption was made that the difference is most likely a consequence of the variability of densities and structure parameters (annual rings, growth conditions), rather than of wood aging process. The relationship between the longitudinal modulus of elasticity and the wood density was almost the same for aged and fresh wood samples.

Relying on a comparative analysis of the works performed by different authors, Pishchik I.I. (Russia) came to the conclusion that long-term preservation of wood in old structures is ensured by certain environmental conditions. Consequently, having performed the appropriate research, the man can learn to do this as well [10].

It is possible that large scatter of research results obtained by different researchers [11 - 13] in this aspect is explained by the peculiarities of forest and nature and climatic conditions affecting formation of wood itself and 
changes in its properties during prolonged exploitation in different geographical regions.

Therefore, research into technical quality of wood of old structures to identify the possibility of its rational and targeted use is relevant today and has practical focus on solving economic and environmental problems [14 - 16].

\section{MATERIALS AND METHODS}

Study of physical and mechanical properties of aged coniferous wood was carried out on the samples taken for performing colorimetric and ultrasound studies from a 70-year-old wooden structure (a former residential building) (Fig. 1) [4]. This work was carried out according to the method of sampling for express diagnostics of wood properties in buildings [17]. 13 samples of spruce (Píceaabies) and 34 samples of pine (Pinussylvestris) of natural stable humidity with dimensions of $20 \times 20 \times$ $300 \mathrm{~mm}$ were used in accordance with GOST 16483.384 [18] and $20 \times 20 \times 30 \mathrm{~mm}$ in accordance with GOST 16483.10-73 [19].

First, $700 \mathrm{~mm}$ long shock bolt-fragments were cut out and removed from the wall logs of the house (Fig. 1). They were selected from three external sides of the house and one internal, the veranda of the house. If possible, this was carried out on every second log and at three points: 2 shock bolt-fragments were taken at a distance of no less than $0.5 \mathrm{~m}$ from the timber work (angular connection of the log house) and 1 - from the center of each side. However, due to the design features of the house, its condition at the time of the study and other factors restricting access, they were not cut and removed from each point described above.

Moisture was measured for each log cut using a GANN COMPACT non-contact electrical hygrometer (Gann Messu. Regeltechnik GmbH, Germany). Shock bolt-fragments of logs were sawn with a Stihl 250 MS chainsaw

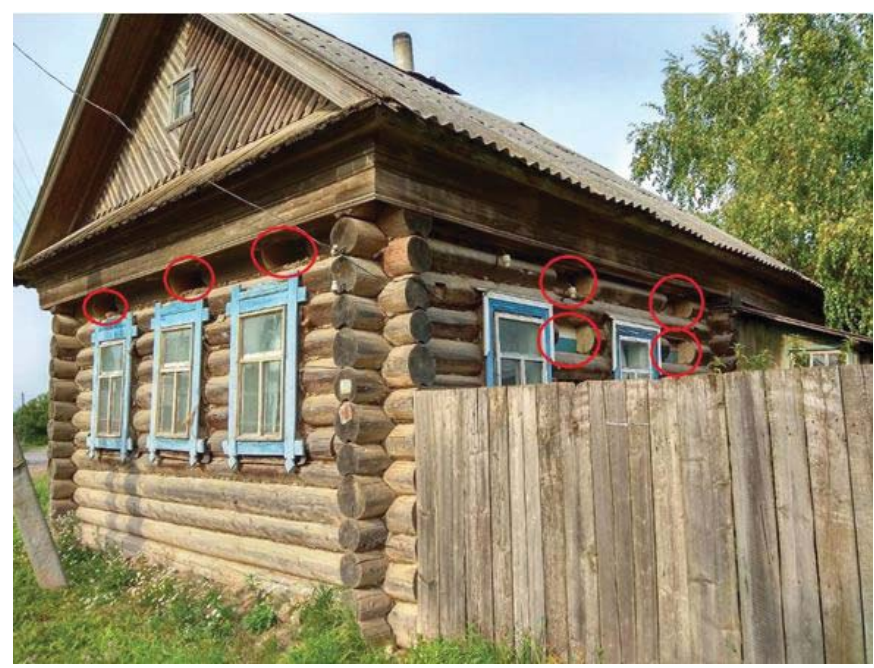

Figure 1: Facade wall (3 windows) and southern wall (2 windows) of the object of study (ovals mark the places for selecting shock bolt-fragments from the house)
(STIHL Holding AG \& Co. KG, Germany).

Samples for study were made from the obtained parts of the logs. Each sample was marked and numbered (identified) depending on the cardinal direction where it was located in the structure, as well as the height of the log. It should be noted that in view of the destruction of wood by rot, cracks, etc. it was possible to cut suitable samples for research from only 22 pieces out of 36 shock bolt-fragments located at the northern, eastern, southern, north-western and south-eastern parts of the walls of the house (see Fig. 2).

Determination of the static bending strength of aged wood was carried out according to GOST 16483.3-84 standard Wood. A method for determining the strength under static bending [18]. The samples were made in the form of a rectangular prism with cross section of $20 \times 20$ $\mathrm{mm}$ and length along the grain of $300 \mathrm{~mm}$. The static bending strength (MPa) wascalculated by the formula

$\sigma_{w}=\frac{3 P_{\max } \cdot l}{2 b h^{2}}$

where $P_{\max }$ is maximum load, $\mathrm{N} ; /$ is bearing distance, $\mathrm{mm} ; b$ is sample height, $\mathrm{mm}$; his sample width, $\mathrm{mm}$.

Determination of the compressive strength along the grains of aged wood was carried out according to GOST 16483.10-73 standard Wood. Methods for determining the compressive strength along the grain[19]. Samples in this study were made with cross section dimensions of $20 \times 20 \mathrm{~mm}$ and along the grain length of $30 \mathrm{~mm}$. In order to obtain comparable results, these samples were sawn from the end parts of the same samples on which the static bending strength of wood was previously studied.
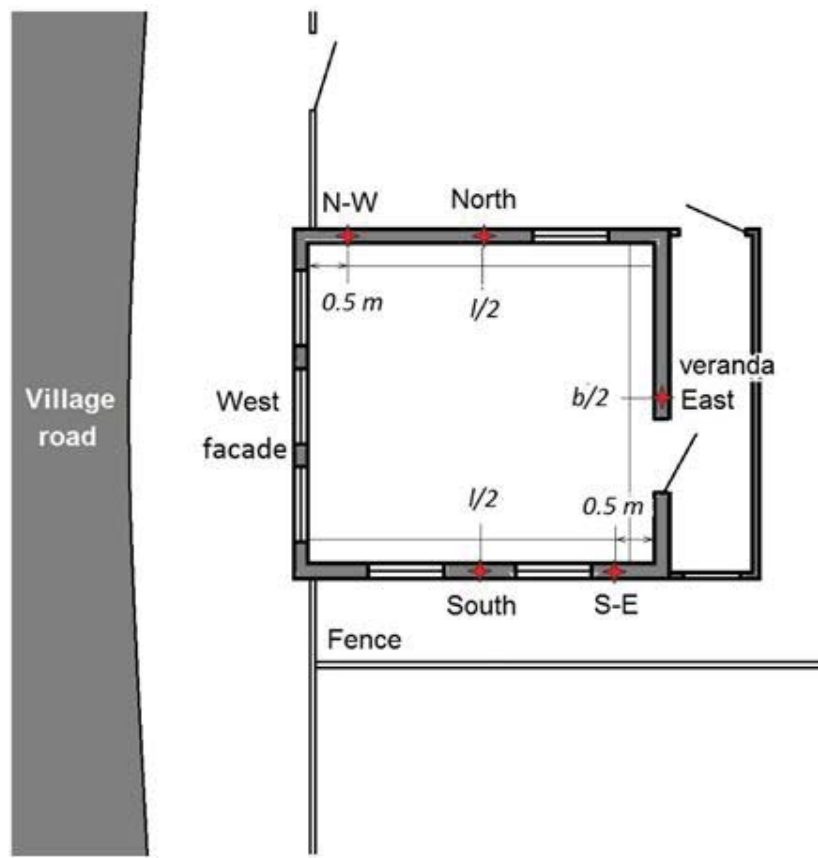

Figure 2: Plan of the house, location of the places for selecting shock bolt-fragments in relation to the cardinal points and relative to the length of each wall (red star) 
The ultimate compressive strength along the grain (MPa) was determined by the equation

$\sigma_{w}=\frac{P_{\max }}{a \cdot b}$

where $P_{\max }$ is maximum load, $\mathrm{N}$; $a$, bare sample thickness and width, accordingly, $\mathrm{mm}$.

A diagram of radial samples selecting and manufacturing from sawn log shock bolt-fragments is presented in Fig. 3.

In both cases samples were conditioned and studied at an equilibrium moisture content of $6-10 \%$. The humidity was obtained by keeping the samples under standard conditions: temperature of $20^{\circ} \mathrm{C}$ and relative humidity of $65 \%$. Such moisture content may be associated with changes in the organic composition of the wood during aging. Similar but more drastic changes are traced at thermal wood modification [20-22], whereby thermowood obtains humidity no more than $1-3 \%$ in conditioning and $4-7 \%$ after humidification. This is mainly due to a decrease in the relative content of hemicellulose fraction, i.e. pentosans and hexosans, with simultaneous increase in lignin. As a consequence, in old wood, as well as in thermally modified one, sorption hysteresis is considerably smaller than that in freshly cut wood, and itsequilibrium moisture content becomes less.

To measure the ultimate strength, we used the Shimadzu Autograph AG-50kNXD testing machine with installed Trapeziumx (Shimadzu, Japan) software for displaying and processing data. A caliper with measurement error of no more than $0.1 \mathrm{~mm}$ was used in the studies.

\section{RESULTS AND DISCUSSION}

The main statistical values of the experimental study results of compressive strength along the grain and static bending strength depending on the cardinal points and separately for the species of aged wood are given in Tab. 1, 2 and Fig. 4, 5 (Box-plots). The experimental data were processed with Statistica program (Stat Soft, Tulsa, USA). For data analysis T-test for independent samples by variables was used, including Box \& whisker plot. The data were obtained at a significance level of $\mathrm{p}=0.05(95 \%)$.

Table 1: Main statistical indicators depending on the cardinal points

\begin{tabular}{|l|c|c|c|c|c|}
\hline Cardinal point & Valid N & Mean & Minimum & Maximum & Std.Dev. \\
\hline \multicolumn{7}{|c|}{ 1. Compressive strength along the grain } \\
\hline East(E) & 13 & 51.1 & 39.7 & 74.9 & 10.27 \\
\hline North (N) & 13 & 49.2 & 36.2 & 101.0 & 16.20 \\
\hline Northwest (N-W) & 10 & 46.2 & 30.6 & 101.0 & 20.39 \\
\hline South (S) & 10 & 59.9 & 40.6 & 78.0 & 13.81 \\
\hline Southeast (S-E) & 4 & 48.5 & 46.1 & 50.7 & 2.34 \\
\hline \multicolumn{7}{|c|}{ 2. Static bending strength } \\
\hline East(E) & 13 & 76.5 & 26.5 & 117.9 & 20.94 \\
\hline North (N) & 13 & 84.9 & 68.7 & 94.4 & 7.47 \\
\hline Northwest (N-W) & 10 & 72.0 & 29.0 & 90.0 & 18.26 \\
\hline South (S) & 10 & 118.0 & 70.3 & 169.9 & 32.24 \\
\hline Southeast (S-E) & 4 & 83.6 & 74.0 & 106.4 & 15.31 \\
\hline
\end{tabular}

Table 2: Main statistical indicators depending on the species

\begin{tabular}{|l|c|c|c|c|c|}
\hline \multicolumn{1}{|c|}{$\begin{array}{c}\text { Species } \\
\text { part of a tree) }\end{array}$} & Valid N & Mean & Minimum & Maximum & Std.Dev. \\
\hline \multicolumn{7}{|c|}{ 1. Compressive strength along the grain } \\
\hline Ag. Pineheartwood & 28 & 52.7 & 30.6 & 101.0 & 18.48 \\
\hline Ag. Pinesapwood & 6 & 47.5 & 39.4 & 62.8 & 10.22 \\
\hline Ag. Spruce & 13 & 48.0 & 39.0 & 59.1 & 6.00 \\
\hline \multicolumn{7}{|c|}{ 2. Static bending strength } \\
\hline Ag. Pineheartwood & 28 & 85.1 & 26.5 & 160.7 & 28.05 \\
\hline Ag. Pinesapwood & 6 & 78.7 & 26.5 & 117.9 & 30.21 \\
\hline Ag. Spruce & 13 & 92.8 & 74.0 & 169.9 & 25.41 \\
\hline
\end{tabular}




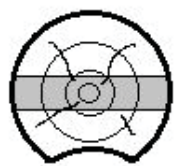

1. fragment of a wall log (getting a core board)
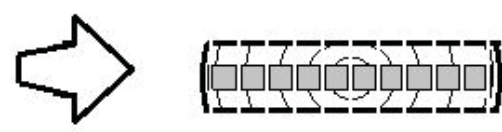

2. core board longitudinal cutting (obtaining standard samples)
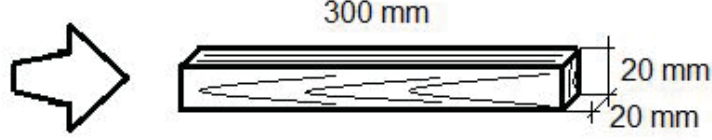

3. standard sample

Figure 3: Sampling and manufacturing scheme
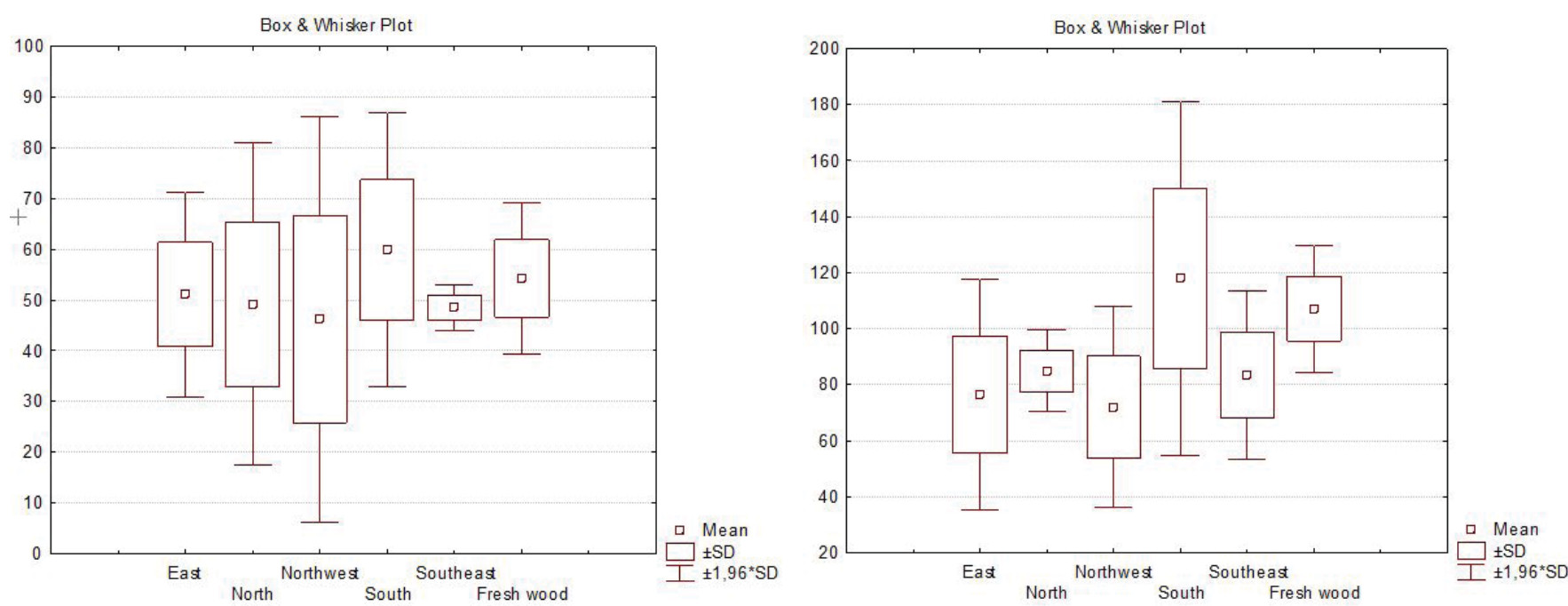

Figure 4: Box-plots of the ultimate compressive strength along the grain (left) and static bending (right) depending on the cardinal points (including the part of the pine) of the wood compared to freshly cut spruce wood, MPa
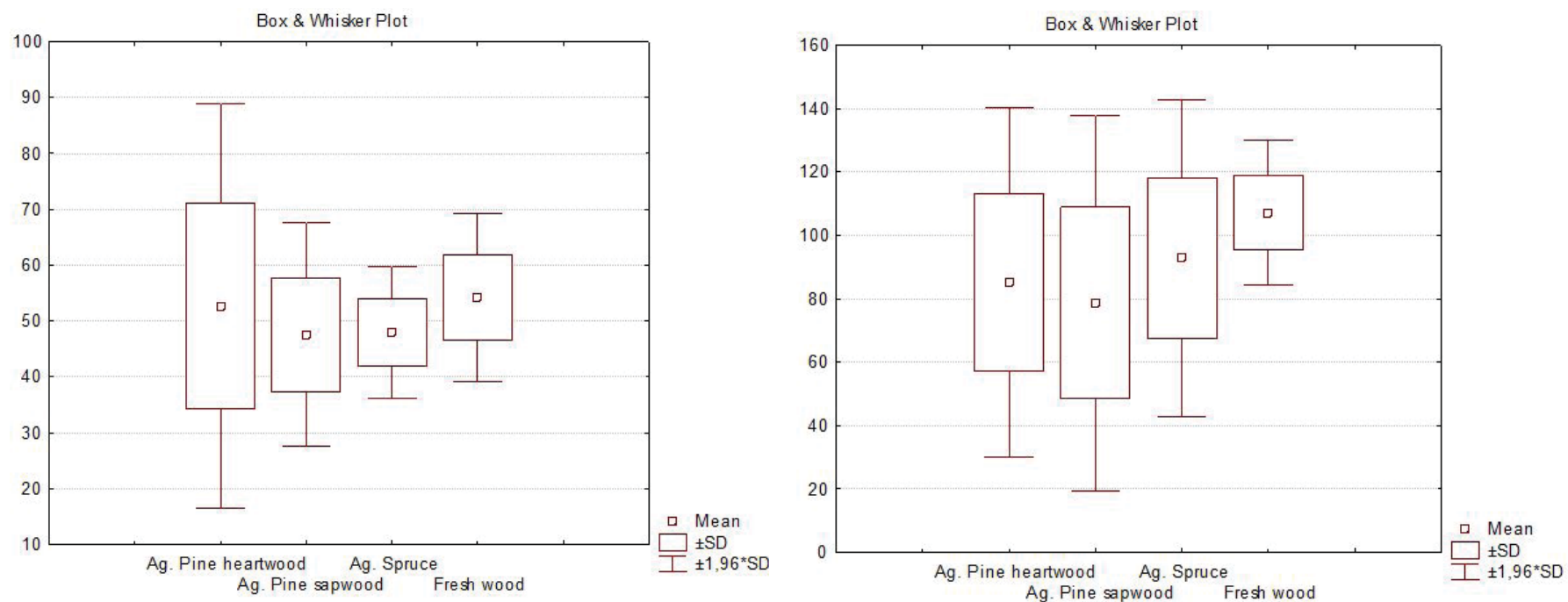

Figure 5: Box-plots of compressive strength along the grain (left) and static bending (right) depending on the species (including the part of the pine) of the wood compared to freshly cut spruce wood, MPa

As studies have shown, the equilibrium moisture content of aged wood when conditioning the samples $\left(t=20^{\circ} \mathrm{C}\right.$, $\varphi=65 \%$ ) was no more than $8 \%$. Therefore, according to Eq. (3) [18], [19], experimental values for $12 \%$ and $30 \%$ humidity were recalculated (Tab. 3$)$ :

$B_{12}=B_{w}[1+\alpha(W-12)]$

where $B_{12}$ is the value of strength at $12 \%$ humidity, MPa; $B_{w}$ is the value of strength at given humidity, MPa; $\alpha$ is correction factor (for all species $\alpha=0.04$ ); $W$ is given value of, moisture content $\%$.
It is evident from the data obtained (Fig. 4, 5) that there is a significant difference in strength characteristics of aged wood depending on the cardinal point. So, the wood selected from the southern side of the house has the highest strength. The mean values of the compressive strength along the grains are higher by $25 \%$, and the static bending is higher by $50 \%$ compared to the samples taken from other sides of the house relative to the cardinal points.

The places of shock bolt-fragments selected between the windows on the south side of the house are shown in Fig. 6. 


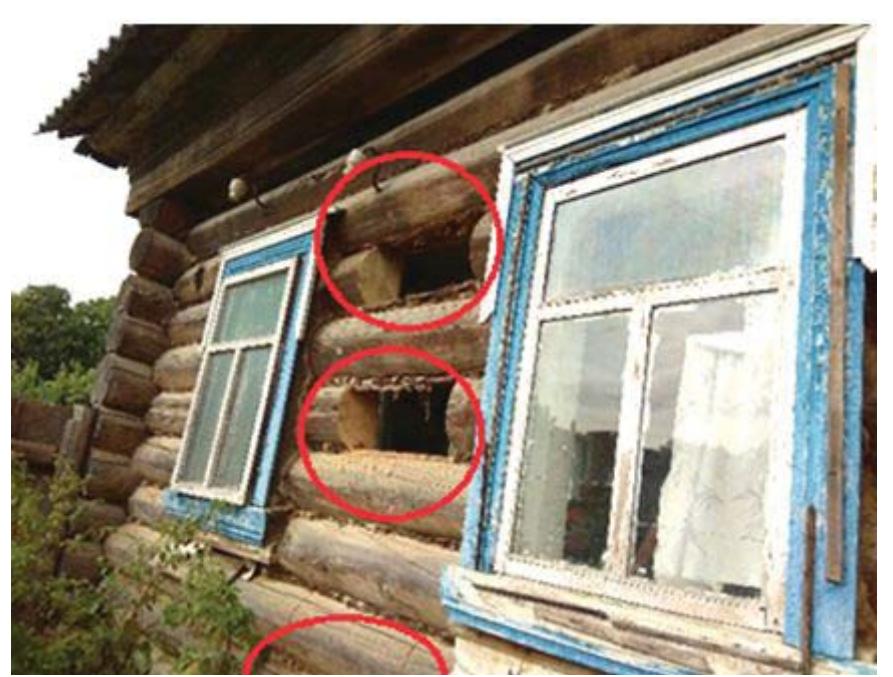

Figure 6: The south side of the house (red ovals mark the places for selecting shock bolt-fragments for test samples)

Among the strength values of samples fromthe parts of the house from other cardinal points, there was no significant difference.

Since samples of different specieswere studied, it can be assumed that the determining factor of such high mechanical values is not the species, but rather the cardinal point.

It is known that in central Russia, the predominant amount of solar energy is received by structural elements of various structures, including wooden ones, located on the south side of them. Therefore, the most pronounced difference in temperature and humidity conditions during the day is observed there. A particularly significant difference is in the winter months of a year. Thus, wood located on the southern side is most affected by climatic and weather conditions, fluctuations of which can create significant stresses inside the material, as a result of which mechanical and acoustic properties can also increase during exploitation, which is confirmed to some extentby other works in this field [9,23-25].

The results analyzed for certain species confirm that the laws governing the variation of strength values for both compression along the grains and static bending, depending on the cardinal points, are identical for pine and spruce.

\section{CONCLUSIONS}

Pine and spruce wood aged in old structures differs in its physical and mechanical properties from fresh wood. On the basis of core statistical indicators obtained withT-test for independent samples by variables and Box\&whisker plot analysis, it was elicited thatafter a long period of exploitation of the structure (70 years or more), coniferous wood has higher strength values in its southern walls than in other three walls; compressive strength along the grains exceeds by $25 \%$, static bending - by $50 \%$.

The wood aged in the walls on the northern, eastern and western sides of the house does not significantly differ in these mechanical values.

It is important to note that under the same conditions of natural conditioning or storage, aged wood gains less stable humidity compared to fresh wood by an average of $2-4 \%$. This can be an advantage for musical instruments and acoustic panels manufactured from such a material, since such wood acquires stability with respect to high physical and mechanical properties, including rigidity, which gives the material better resonant properties.

The static bending strength during aging became higher for spruce than for pine wood. According to other mechanical indicators, aged wood did not reveal any dependence on the species.

The results obtained in this work encourage the development of the topic and are directed at more in-depth studies in this area, including the study of influence of the cardinal point on the acoustic and colorimetric properties of wood in old buildings, which are the main criteria for resonant material quality.

\section{REFERENCES}

1. Ugolev, B.N. (2007) Wood Science and Forest Commodity Science. M: MGUL.

2. Ugolev, B.N. (2001) Wood science with basic concepts of timber merchandizing. - M: MGUL, $340 \mathrm{p}$.

3. Bucur V. (2016). Handbook of Materials for String Musical Instruments. In: Springer International Publishing. Switzerland, DOI: 10.1007/978-3-31932080-9.

4. Fedyukov, V.I. (2018) Non-destructive method for express-diagnostics of resonant properties of wood aged in old structures / V.I. Fedyukov, V.Yu. Chernov, M.S. Chernova, N.A. Magalyas, O.V. Tsoy // Wood structure, properties and quality - 2018: Materials of VI International Symposium after B.N. Ugolev, dedicated to the 50th anniversary of the Regional Coordinating Council on modern problems of wood science (Krasnoyarsk, 10-16 September 2018) Novosibirsk: SB RAS printing house.

5. Fedyukov, V.I. (2016) Resonant spruce: selection from stands, cultivation, intended use: monograph. Volga State University of Technology. 256 p.

6. Gusev, B.P. (1999) Church of the Transfiguration in Kizhi. Considering the properties and condition of the log structure timber in the course of restoration // Actual problems of research and recovery of unique monuments of wooden architecture. SPb., pp.106112.

7. Terentyev B.Ya., Nikonov N.I., Soushinskaya R.I. (1998) Mechanical properties of pine wood after prolonged use in the supporting structures of buildings. M.: Woodworking industry, No.7,pp.15-17. 
8. Keskkulla, T.E. (1986) Operability of agricultural production buildings: Doctoral thesis. Tartu, 398 p.

9. Kranit z, K., Deublein, M., Niemz, P. (2013) Determination of Dynamic Elastic Moduli and Shear Moduli of Aged Wood by Means of Ultrasonic Devices. In: Materials and Structures 2013, 47-55, DOI: 10.1617/ s11527-013-0103-8.

10. Pishchik I.I. (2014) Dating of wooden monuments: monograph / I.I. Pishchik; Ministry of education and science of the Russian Federation, FSBEl HPE 'Moscow State University of Forest'. M.: Moscow State University of Forest Publishing House. 161 p.

11. Isayeva T.I., Brukhanova N.K. (1969) Study of the properties of wood and wood materials // Collection of works of the Institute of the forest and wood, SB of the USSR AS, Krasnoyarsk.

12. Kozlov V.A., Kroutov V.I., KisternayaM.V. (1996) Methodological bases for assessing the wood condition of the Church of Transfiguration in the Kizhi Museum-Preserve // Proceedings of the II International Symposium: Structure, Properties and Quality of Wood-96, October 1996, MGUL, M., pp.307-312.

13. Shapovalova L.G. et al. (1996) Physical and mechanical properties of larch wood during long-term exploitation // Proceedings of the II International Symposium: Structure, properties and quality of wood-96, October 1996, MGUL, M., pp. 246-250.

14. Andreyev, N.N. (1938) On the tree for musical instruments. Collection of works, CMSRL. M.L., pp. 11-18.

15. Borovikov A.M., Ugolev B.N. (1989) Timber reference-book: Reference-book / Ed. by B.N. Ugolev. M.: Timber industry. $296 \mathrm{p}$.

16. Obataya $E$ (2009) Effect of ageing and heating on the mechanical properties of wood. In: Proc "Wood science for conservation of cultural heritage", COST action IE 0601, Firenze Univ. Press, Florence, Italy, pp. 16-23.
17. Patent of invention RU 12665149 C1 for Method for express diagnostics of resonance properties of wood aged in old structures / V.I. Fedyukov, V.Yu. Chernov, M.S. Chernova, N.A. Magalyas, O.V. Tsoy, IPC G01N 33/46. Appl. 07.08.2017; Publ. 28.08.2018. Bul. No 25.

18. GOST 16483.3-84 (СТСЭB 390-76) (1999) Wood. Method for determining the tensile strength in static bending - M.: Standards publishing.

19. GOST 16483.10-73 (1999) Wood. Methods for determining compressive strength along grains - M.: Standards publishing.

20. Kranit z, K., Sonderegger, W., Bues, C.-T., Niemz, P. (2015). Effects of aging on wood: a literature review. Wood Science and Technology. 50. 10.1007/ s00226-015-0766-0.

21. Matsuo, M., Yokoyama, M., Umemura, K., et al. (2011). Aging of wood: Analysis of color changes during natural aging and heat treatment. Holzforschung, 65(3), pp. 361-368. Retrieved 30 Oct. 2019, from doi:10.1515/hf.2011.040.

22. Finnish Thermo Wood Association: Thermo Wood Handbook. Helsinki,Finland (2003).

23. Froidevaux J, Navi P (2013) Ageing law of spruce wood. Wood Mat SciEng 8(1):46-52.

24. Kranit z K. (2016) Effects of aging on wood: a literature review. In: Springer-Verlag Berlin Heidelberg 2015, 7-16, DOI: 10.1007/s00226-015-0766-0.

25. Yokoyama M, Gril J, Matsuo M, Yano H et al (2009) Mechanical characteristics of aged hinoki (Chamaecyparisobtusa) wood from Japanese historical buildings. In: Proceedings wood science for conservation of cultural heritage, October 7-10, COST Action IE 0601. Hamburg, Germany. Paper Session 4. 9 pp.

Paper submitted: 02.09.2019.

Paper accepted: 17.11.2019.

This is an open access article distributed under the CC $B Y-N C-N D 4.0$ terms and conditions. 